\title{
ASPECTOS MORFOLÓGICOS DA COLONIZAÇÃO DE Colletotrichum gloeosporioides EM ÓRGÃOS DE PLANTAS DE CAFEEIROS E COM SINTOMAS DA MANCHA MANTEIGOSA
}

\author{
Morphologic aspects of colonization of Colletotrichum gloeosporioides \\ on organs of coffee plants with blister spot
}

\author{
Josimar Batista Ferreira' ${ }^{1}$, Mario Sobral de Abreu ${ }^{2}$ Eduardo Alves $^{3}$, Igor Souza Pereira ${ }^{4}$
}

\begin{abstract}
RESUMO
Objetivou-se, no presente trabalho, analisar microscopicamente a colonização de C. gloeosporioides, agente da mancha manteigosa (MM), em condições naturais da doença, sobre os diferentes órgãos e tecidos da cultivar Catucaí Vermelho: folhas, pecíolos, nervuras, ramos, frutos e pedúnculos. Todas as amostras foram processadas, obtendo-se imagens em microscópico eletrônico de varredura. Os ramos e as nervuras de folhas de cafeeiros com mancha manteigosa apresentando morte descendente e hipocótilos oriundos de sementes têm os vasos do xilema, floema e células do córtex colonizados por $C$. gloeosporioides, já os frutos com sintoma da mancha manteigosa apresentaram colonização nos tecidos do exocarpo, mesocarpo, endocarpo e endosperma.
\end{abstract}

Termos para indexação: Cafeeiro, antracnose, microscopia eletrônica de varredura.

\begin{abstract}
The aim of this work was to study the colonization of leaves, petioles, veins, branches, fruits, and peduncles by $C$. gloeosporioides, the causal agent of blister spot, under natural infections of cultivar Catucaí Vermelho in field conditions. All materials were analyzed through scanning electron microscopy. The branches and veins of coffee leaves affected by blister spot with descending death as well as hypocotyls from seedlings had their xylem, phloem and cortical cells colonized by C. gloeosporioides while fruits showing blister spot symptoms had their exocarp, mesocarp, endocarp, and endosperm tissues colonized by $C$. gloeosporioides.
\end{abstract}

Index terms: Coffee tree, anthracnose, scanning electron microscopy.

(Recebido em 25 de maio de 2007 e aprovado em 3 de junho de 2008)

\section{INTRODUÇÃO}

A mancha manteigosa foi relatada em Coffea arabica L., em 1957, por Wellman (1957), na Costa Rica, reportando-se de natureza virótica, mas sem conseguir demonstrar a sua transmissão. Posteriormente, Vargas \& González (1972) demonstraram ser ocasionada por um fungo do gênero Colletotrichum. Orozco Miranda (2003), utilizando técnicas de RAPD e SSRs, comprovou que os isolados provenientes de plantas com sintomas da mancha manteigosa referem-se à Colletotrichum gloeosporioides.

No Brasil, os primeiros relatos datam de 1958, feitos por Bitancourt (1958) que descreveu no estado de São Paulo, uma enfermidade em folhas de Coffea arabica com sintomas nas folhas novas onde aparecem, inicialmente, manchas de cor verde-clara, de aspecto oleoso, menos brilhante que a superfície da folha, medindo de 2 a $10 \mathrm{~mm}$ de diâmetro. Em estágios avançados, as manchas apresentam coloração verde-pálida a amarela e bordas irregulares, que chegam a coalescer, determinando queda prematura das folhas. Esse autor descreve que, nos ramos e frutos, as lesões são menores, com 2 a 3 mm de diâmetro, deprimidas, necróticas de cor marrom-clara e bordas irregulares.

Essa doença, tem gerado em algumas regiões perda da produção nas plantas doentes, (COSTA et al., 2003; LINS et al. 2008; FERREIRA et al., 2009a) e se encontra disseminada na maioria de nossos estados produtores de café (Minas Gerais, Espírito Santo, São Paulo, Paraná e Rondônia), nas espécies Coffea arabica L. e Coffea canephora Pierre ex Froenher.

Colletotrichum spp. têm sido encontrados associadas a todos os órgãos do cafeeiro: folhas, frutos,

\footnotetext{
'Engenheiro Agrônomo, Doutor em Fitopatologia - Centro Multidisciplinar/CMULT - Universidade Federal do Acre/UFAC - Campus Floresta, Estrada Canela Fina, Km 12 - Gleba Formoso, Lote 245 - Colônia São Francisco - 69980-000 - Cruzeiro do Sul, AC - josimarferreira@gmail.com

${ }^{2}$ Engenheiro Agrônomo, Doutor em Fitopatologia - Departamento de Fitopatologia/DFP - Universidade Federal de Lavras/UFLA - Cx. P. 3037 - 37200 000 - Lavras, MG - msabreu@bol.com.br

${ }^{3}$ Engenheiro Agrônomo, Doutor em Fitopatologia, Laboratório de Microscopia - Departamento de Fitopatologia/DFP - Universidade Federal de Lavras/ UFLA - Cx. P. 3037 - 37200-000 - Lavras, MG - ealves@ufla.br

${ }^{4}$ Engenheiro Agrônomo, Mestre em Fitopatologia - Departamento de Fitopatologia/DFP - Universidade Federal de Lavras/UFLA - Cx. P. 3037 - 37200 000 - Lavras, MG - igorreloi@yahoo.com.br
} 
flores e ramos. Em frutos verdes, observam-se mumificações com conseqüente queda dos mesmos. Em folhas e ramos novos de plantas adultas, ocorrendo necrose e seca dos ramos na parte apical, podem levar à morte das plantas de forma descendente (FERREIRA, 2009a; FERREIRA et al., 2009b).

Os estudos até o momento, para o patossistema Colletotrichum spp. e cafeeiro no Brasil, têm sido dirigidos à etiologia do patógeno, à patogenicidade e à caracterização de isolados. Poucos estudos têm sido voltados para as alterações morfológicas na interação patógenohospedeiro. Uma compreensão dos eventos de prépenetração, de como o patógeno infecta e coloniza o hospedeiro e como a planta estabelece mecanismos de resistência pré e pós-formados, é fundamental para o estabelecimento de medidas de controle da doença (BAILEY et al., 1992; HARDHAM, 1992; HOCH \& STAPLES, 1987; LOPEZ, 2001; MILHOLLAND, 1982; NAIR \& CORBIN, 1981; PORTO et al., 1988; ROBERTS \& SNOW, 1984).

Objetivou-se, neste estudo, verificar a colonização de C. gloeosporioides, em condições naturais da doença sobre folhas, pecíolos, nervuras, ramos, frutos e pedúnculos.

\section{MATERIAL E MÉTODOS}

Os experimentos foram conduzidos nos Laboratórios de Diagnose e Controle de Enfermidades de Plantas e de Microscopia Eletrônica e Análise Ultraestrutural (LME) no Departamento de Fitopatologia da Universidade Federal de Lavras (UFLA), Lavras, MG.

\section{Coleta das amostras e caracterizações morfológicas}

Foram realizadas coletas, em plantas sadias e doentes de cafeeiro com mancha manteigosa, cultivar Catucaí Vermelho, diferentes órgãos e tecidos do cafeeiro: folhas, pecíolos, nervuras, hipocótilos, ramos, frutos e pedúnculos.

Inicialmente, parte dos materiais coletados foram submetidos a exames laboratoriais para identificação e caracterização do agente causal, utilizando-se a chave taxonômica descrita por Sutton (1992), comparando também com as descrições de Orozco Miranda (2003) em seus estudos de caracterização morfológicas de isolados de Colletotrichum spp. associados ao cafeeiro.
Estudos da colonização de $C$. gloeosporioides em condições naturais da doença

Todos os materiais foram imersos em solução fixativa (Karnovisky modificado - glutaraldeido 2,5\%, paraformaldeido 2,0\%, tampão cacodilato $0,05 \mathrm{M}, \mathrm{pH} 7,2$ ), acondicionados em tubos "eppendorfs" de 1,5 mL. Todos esses materiais sofreram processo de criofratura em nitrogênio líquido.

\section{Preparo das amostras para corte em nitrogênio líquido}

Amostras fixadas como descrito anteriormente, foram transferidas para glicerol $30 \%$, por 30 minutos. Em seguida, cada sub-amostra foi imersa em recipiente plástico contendo nitrogênio líquido e cortados com bisturi sobre placa de metal submergida em recipiente de isopor (térmico) também contendo nitrogênio líquido. Cada sub-amostra foi seccionada nos sentidos transversais e longitudinais e, em seguida, foram transferidas para "eppendorfs" contendo água destilada.

\section{Preparo das amostras para microscopia eletrônica de varredura (MEV)}

A preparação das amostras foi realizada no laboratório de Microscopia e Análise Ultra-estrutural (LME), no Departamento de Fitopatologia da Universidade Federal de Lavras, UFLA, MG segundo protocolo padrão do laboratório descrito por Alves (2004).

\section{Observação de imagens em MEV}

As amostras devidamente preparadas e identificadas foram examinadas ao microscópio de varredura LEO EVO 40XVP. As imagens foram geradas e capturadas digitalmente, nas condições de trabalho de $20 \mathrm{Kv}$ e distância variando de 9 a $12 \mathrm{~mm}$. Foi utilizado o Software Photopaint, do pacote Corel Draw 11, no preparo das pranchas apresentadas neste estudo.

\section{RESULTADOS E DISCUSSÃO}

\section{Colonização dos órgãos do cafeeiro com sintoma da mancha manteigosa}

A partir de material infectado naturalmente no campo, eletrofotomicrografias evidenciaram a agressividade de $C$. gloeosporioides isolado da mancha manteigosa. Verificou-se a presença do micélio do em todos os órgãos do cafeeiro, colonizando sistemicamente os tecidos do xilema, do floema, do córtex e as células de endosperma, conseqüentemente provocando morte de ramos, mumificações de frutos e queda de folhas, etc. 
Constatou-se que a metodologia de cortes em nitrogênio líquido utilizando glicerol $30 \%$ como crioprotetor foi apropriada, dando totais condições para as observações das estruturas celulares dos tecidos colonizados pelo fungo.

A partir de cortes em ramos de cafeeiro apresentando necrose e morte descendente, foi possível verificar que o fungo colonizou todos os tecidos (Figura 1). Em cortes transversais, foi possível verificar hifas do fungo colonizando as células do tecido cortical (Figura 1A), em direção aos tecidos de xilema, floema e medular dos ramos. Nos cortes longitudinais, verificou-se colonização das células do parênquima cortical (Figuras 1A e D). Nas células do xilema, as hifas penetraram os tecidos do vaso, colonizando sistemicamente todo o ramo (Figura 1C). No patossistema cafeeiro-mancha manteigosa, segundo Orozco Miranda (2003), Pereira (2005) e Pereira et al. (2009), o fungo coloniza sistemicamente os tecidos, no qual, a partir de um ponto, transloca-se tanto descendente como ascendentemente.
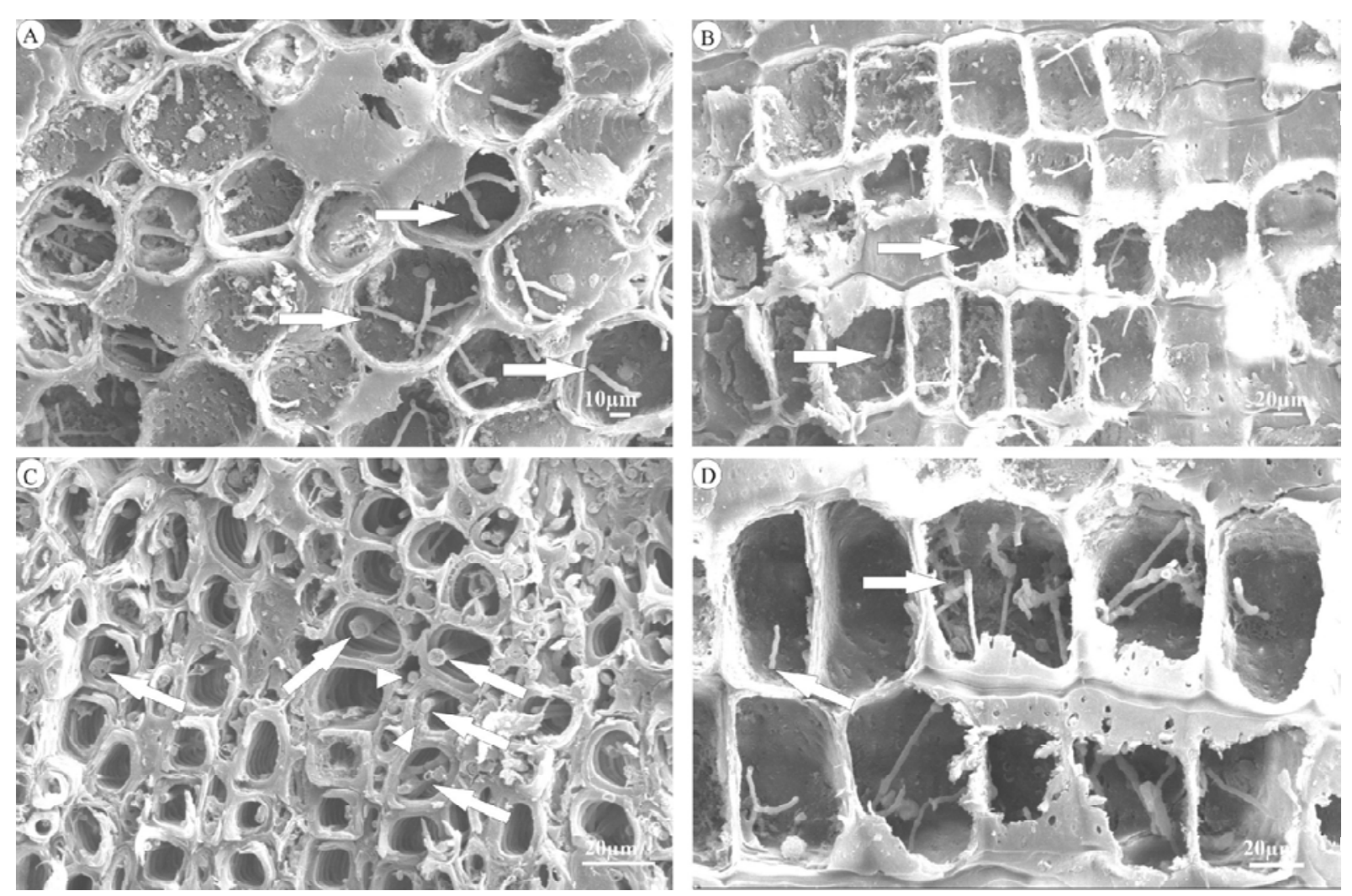

Figura 1 - Eletromicrografias de varredura exibindo a colonização de $C$. gloeosporioides em ramos de cafeeiro com sintoma da macha manteigosa. A e C: Cortes transversais; B e D: cortes longitudinais, mostrando hifas colonizando células do parênquima cortical; C: Corte transversal evidenciando a colonização sistêmica por hifas nos vasos do xilema (setas).

Ciênc. agrotec., Lavras, v. 33, n. 4, p. 956-964, jul./ago. 2009
Diversos autores relatam a gravidade da seca de ponteiros ou morte de ramos, na cultura do café. Voltan et al. (2002) analisando ramos de cafeeiro expressando seca de ponteiro diebeck, observaram alterações na estrutura do córtex e do floema, devido à colonização por Colletotrichum spp., preconizando a dificuldade no controle e no manejo desta doença (FERREIRA et al., 2009a).

Em busca de alternativas para o manejo de $C$. gloeosporioides associado à mancha manteigosa, Ferreira (2009a) e Orozco Miranda (2003) realizaram recepa baixa em plantas doentes, porém não obtiveram o seu controle, concluíram, então que, em plantas com sintomas da doença, as recepas não colaboram para a eliminação desse patógeno, pois ele coloniza o sistema vascular das plantas doentes (PEREIRA et al., 2009) como comprovado em nosso estudo.

Similarmente ao verificado em ramos, foram observados, em nervuras de folhas de cafeeiro com sintomas da mancha manteigosa, a colonização na região do córtex (Figura 2B) e expressiva presença de hifas em vasos do xilema (Figura 2C). 

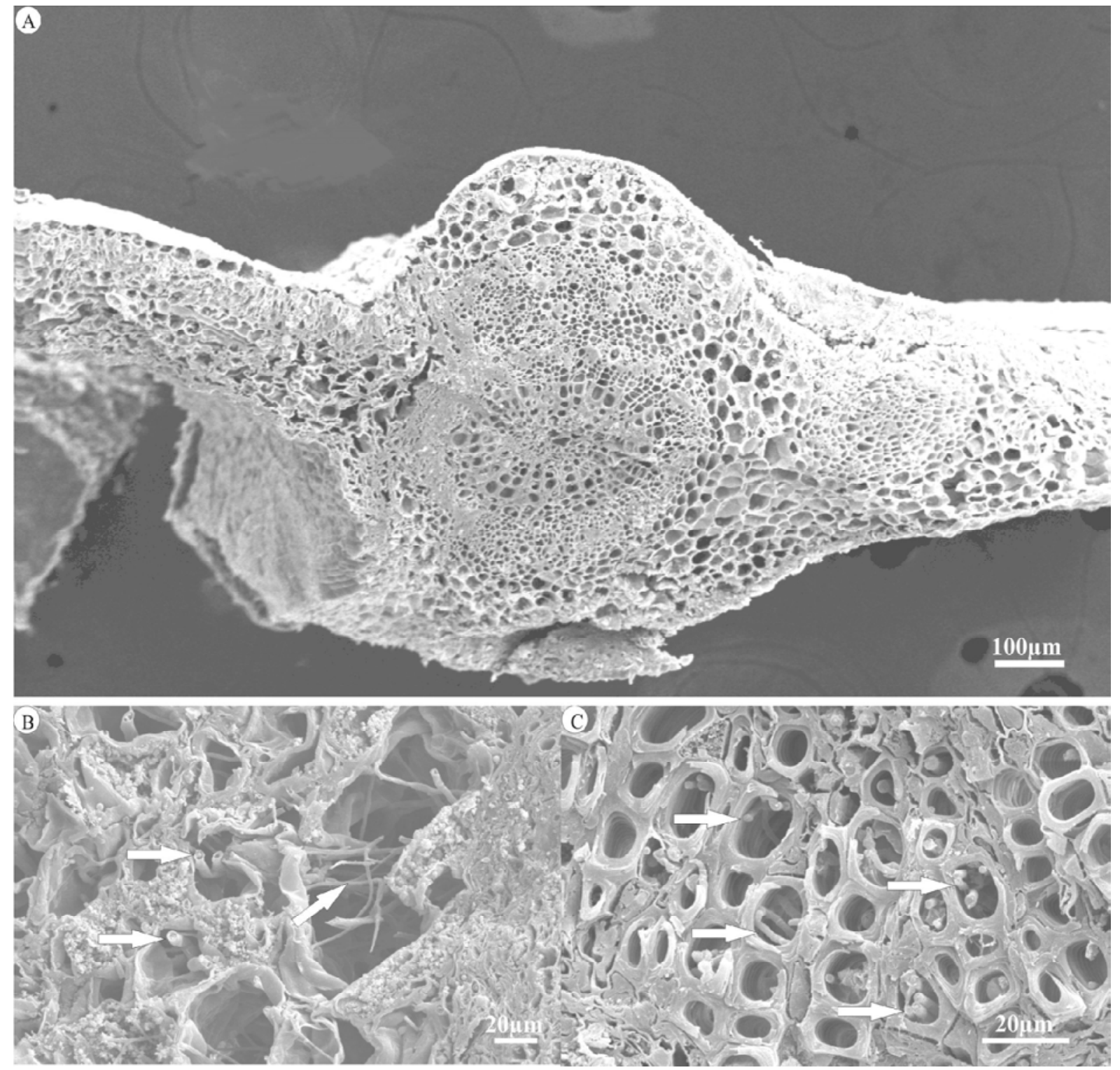

Figura 2 - Eletromicrografias de varredura em nervuras de folhas de cafeeiro. A: corte transversal exibindo todos os tecidos anatômicos B: parênquima cortical; C: vasos do xilema.

Nas observações em endosperma, foi possível verificar presença de hifas colonizando internamente as células do endosperma (Figura 3). As primeiras observações foram realizadas na superfície do endosperma, verificando-se rachaduras expondo hifas de fungo (Figura 3A). Em cortes transversais, observou-se também presença de hifas (Figura 3B e D). Quando foram realizados cortes no endosperma de frutos na fase "verde cana", com sintomas da mancha manteigosa, esses também apresentavam hifas colonizando internamente as células do endosperma (Figuras
3C e E). Em frutos sadios, não se observou a presença de fungos, apenas grãos de amido (Figura 3F).

Quando se estudou a colonização por $C$. gloeosporioides, agente da mancha manteigosa no exocarpo (casca), observou-se uma densa colonização ao centro das lesões. As primeiras imagens foram geradas na superfície dos frutos, os quais apresentavam lesões deprimidas tipo cancro, com degradação das células da epiderme do fruto, tendo formato circular (Figura 4A), em detalhe figura 4B, o centro das lesões exibe aspecto áspero 

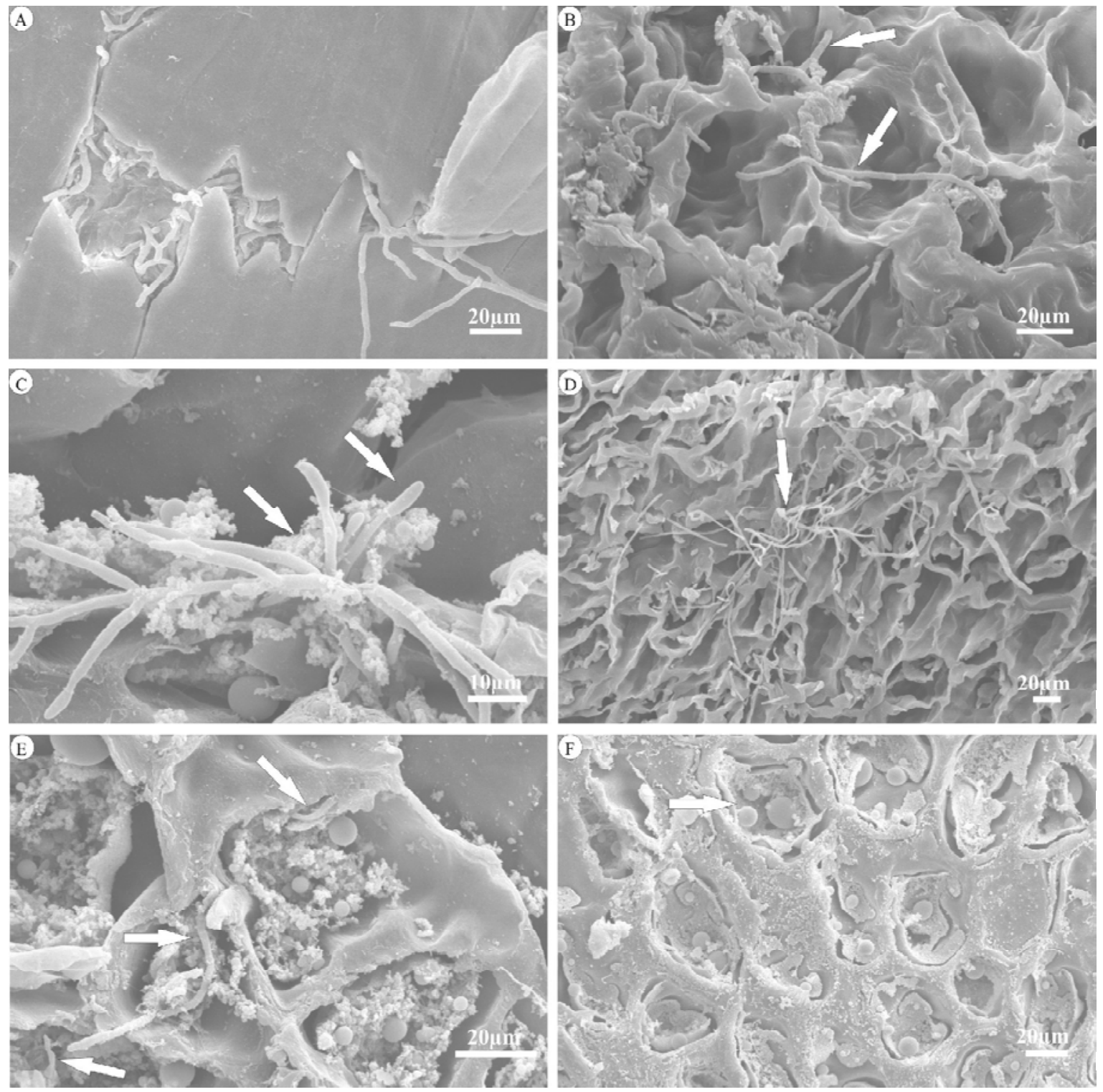

Figura 3 - Eletromicrografias de varredura em endosperma de frutos de cafeeiro com sintoma da mancha manteigosa. A: rachadura externa expondo hifas; B e D: cortes em frutos "secos" exibindo hifas nas células do endosperma; C e E: cortes em frutos "verde-cana" com colonização de hifas (setas); F: fruto sadio com presença de grãos de amido (seta).

(rugoso), com rachaduras e há presença de hifas colonizando os tecidos dos frutos (Figura 4B). Resultados semelhantes foram encontrados por Pereira et al. (2009) que verificaram diferenças no formato e no tipo de lesões entre frutos verdes e frutos maduros. Os mesmos autores, também verificaram que as lesões exibiam formato circular, com aspecto coriáceo quebradiço podendo ser observado a olho nu. Quando fez-se a fratura das amostras, pôde-se observar colonização interna, nos tecidos do exocarpo e mesocarpo, por hifas. Ferreira et al. (2005), em estudos de colonização em frutos maduros de cafeeiro, por meio de inoculação em MEA 2\%, (extrato de malte-ágar), verificaram altos índices de infecção por Colletotrichum. Nos tecidos do exocarpo e mesocarpo, observaram-se, em média, 86,6\%, seguidos pelo endocarpo, com $9,72 \%$ e o endosperma, com $8,3 \%$ de infecção. 
Nas observações realizadas em folhas com sintomas e sem sintomas da mancha manteigosa, não se verificou nenhuma hifa; em folhas de plantas doentes, as lesões apresentavam-se de formato irregular, tendo deformações nas células epidérmicas, que exibiam aspecto de degeneração dos tecidos (Figura 4C). Quando se realizaram cortes transversais na área lesionada, verificou- se que os tecidos do mesofilo foliar apresentavam-se deformados, exibindo concreções, "material amorfo", nas células do parênquima paliçádico e esponjoso (Figura 4D). Ao realizarem-se cortes em folhas sadias, essas se apresentavam normais, tendo as células dos tecidos paliçádico e esponjoso bem desenvolvidas (Figura 4F).
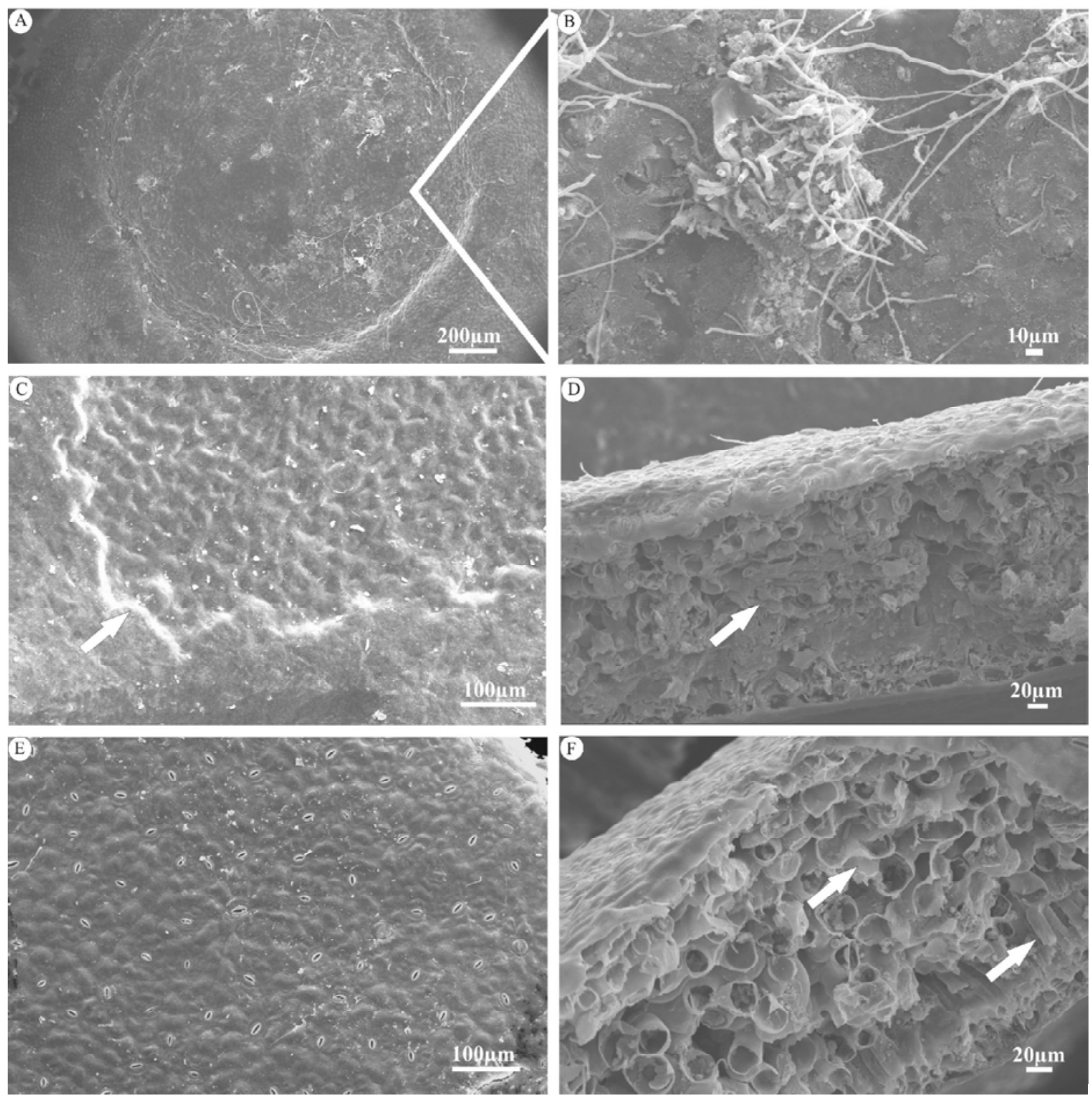

Figura 4 - Eletromicrografias de varredura em frutos e folhas de cafeeiro com sintoma da macha manteigosa. A: lesão em frutos; B: centro da lesão com colonização de Colletotrichum; C: lesão em folhas; D: corte transversal na área lesionada, exibindo degeneração do mesofilo foliar; E: epiderme de folha sadia; F: corte transversal em folha sadia - células íntegras do tecido esponjoso e paliçádico (setas). 
Também foram realizadas investigações em hipocótilos de plantas doentes e de plantas sadias, todas semeadas em areia estéril. Observou-se, em cortes transversais que hipocótilos de plantas doentes exibiam, em seus tecidos, a colonização por Colletotrichum, sendo em maior proporção nas células do parênquima cortical, com degeneração e morte de células nessa região (Figuras
5A e B). Foi também verificado que, em hipocótilos com maior degeneração da região cortical, constatavam-se a presença de acérvulos (Figura $5 \mathrm{C}$ ). Ao passo que, nas observações realizadas em hipocótilos de plantas sadias, todos os tecidos estavam sadios, apresentando grânulos de grãos de amido na região cortical e medular (Figuras $5 \mathrm{D}$ e $\mathrm{E})$.

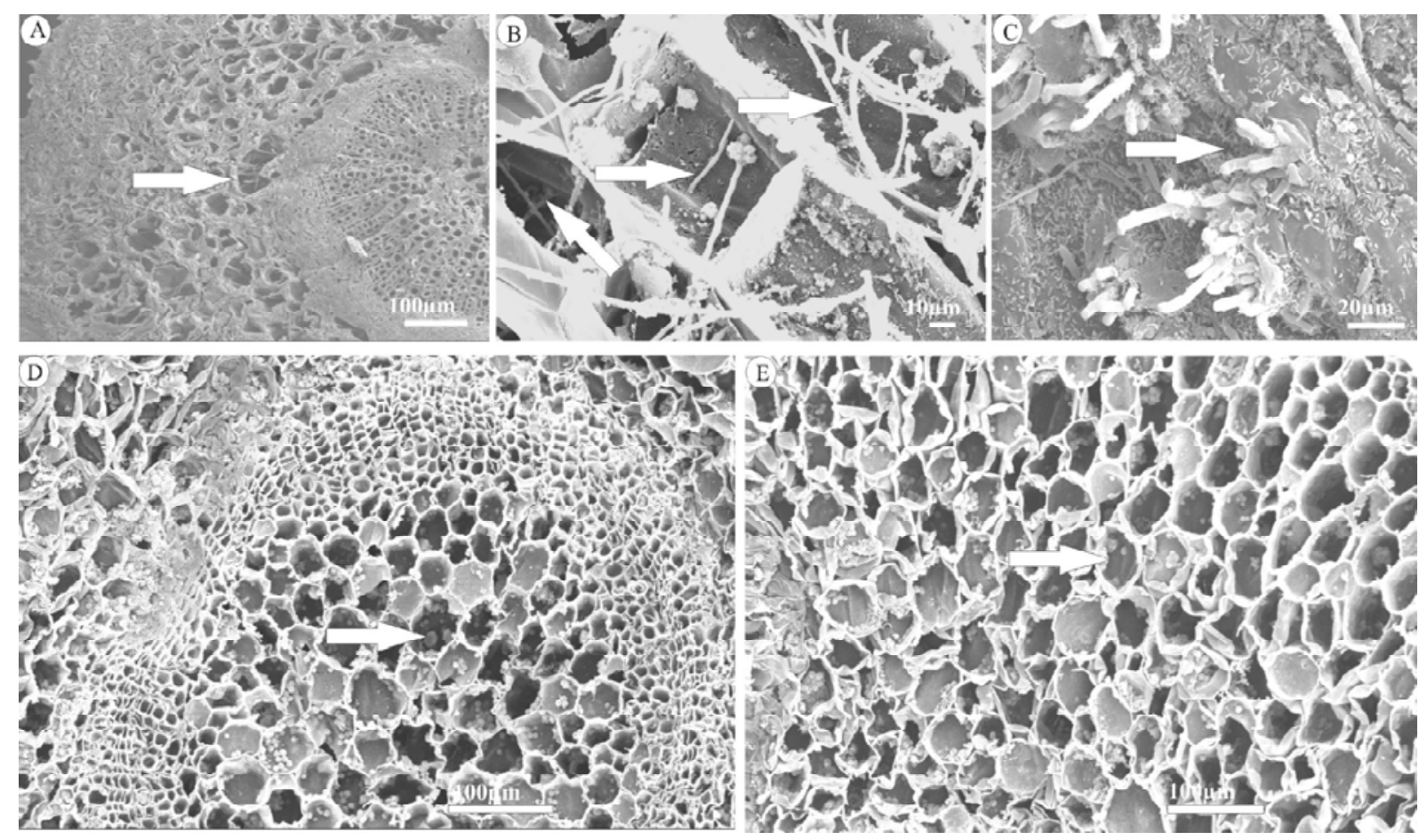

Figura 5 - Eletromicrografias de varredura exibindo a colonização de C. gloeosporioides em hipocótilos de cafeeiro. A e B: degeneração e colonização por hifas na região cortical; C: produção de acérvulos D e E: corte transversal em hipocótilos de planta sadia, com presença de grânulos de amido (seta).

Segundo Lins et al. (2007) em estudos histopatológicos de C. gloeosporioides isolados de plantas de café com mancha manteigosa, evidenciouse até ao sexto dia após a inoculação a colonização dos tecidos do córtex, floema e xilema. Segundo o autor, as hifas perfuraram as células e foram colonizando o tecido do hospedeiro, em todas as direções.

\section{CONCLUSÕES}

Ramos e nervuras de cafeeiros com mancha manteigosa e sintomas de necrose e morte descendente têm os vasos do xilema, floema e células do parênquima cortical colonizados por C. gloeosporioides. Os frutos com sintoma da mancha manteigosa apresentam colonizações por C. gloeosporioides nos tecidos do exocarpo, mesocarpo, endocarpo e endosperma e hipocótilos oriundos de sementes de plantas doentes com mancha manteigosa têm o córtex, xilema e floema colonizados por C. gloeosporioides.

\section{AGRADECIMENTOS}

À FAPEMIG pelo apoio ao LME e a Embrapa-Café pelo financiamento do projeto.

\section{REFERÊNCIAS BIBLIOGRÁFICAS}

ALVES, E. Curso introdutório à microscopia eletrônica de varredura. Lavras, MG: UFLA-FAEPE, 2004. 43 p. Apostila. 
BAILEY, J. A.; O'CONNEL, R. J.; PRING, R. J.; NASCH, C. Infection strategies of Colletotrichum species. In: BAILEY, J. A.; JEGER, M. J. (Eds.). Colletotrichum biology, pathology and control. London: CAB, 1992.

BITANCOURT, A. A. As manchas da folha do cafeeiro. O biológico, São Paulo, v. 24, n. 17, p. 191-201, mar. 1958.

COSTA, H.; VENTURA, J. A.; FERRÃO, M. A. Mancha manteigosa em café arábica na região serrana do Estado do Espírito Santo. In: SIMPÓSIO DE PESQUISA DOS CAFÉS DO BRASIL, 3., 2003, Porto Seguro, BA. Anais... Porto Seguro: Embrapa Café, 2003. p. 206.

FERREIRA, J. B.; ABREU, M. S.; PEREIRA, I. S. Incidência de Colletotrichum spp. em frutos de Coffea arabica $\mathrm{L}$. em diferentes estádios fisiológicos e tecidos do fruto maduro. Ciência e Agrotecnologia, Lavras, v. 29, n. 4, p. 880-885, jul./ago. 2005.

FERREIRA, J. B.; ABREU, M. S.; PEREIRA, I. S. A. Análise da dinâmica, estrutura de focos e arranjo espacial da mancha manteigosa em campo. Ciência e Agrotecnologia, Lavras, v. 33, n.1, p.24-30, jan./fev., 2009a.

FERREIRA, J. B.; ABREU, M. S.; PEREIRA, I. S. A.; FERNANDES, K. D.; PEREIRA, R. B. Efeito de fungicidas e influência de fatores climáticos sobre a mancha manteigosa no cafeeiro. Ciência e

Agrotecnologia, Lavras, v. 33, n. 2, p. 417-424, mar./abr., $2009 \mathrm{~b}$.

HARDHAM, A. R. Cell biology of pathogenesis. Annual Review of Plant Physiology, Palo Alto, v. 43, p. 491-523, 1992.

HOCH, H. C.; STAPLES, R. C. Structural and chemical changes among the rust fungi during appressorium development. Annual Review of Phytopathology, Palo Alto, v. 25, p. 231-247, 1987.

LINS, S. R. O.; ABREU, M. S.; ALVES, E. Estudos histopatológicos da interação Colletotrichum gloeosporioides em plântulas de cafeeiro. Fitopatologia Brasileira, Brasília, v.32, n.6, p.488-495, nov./dez., 2007.

LINS, S. R. O.; ABREU, M. S.; ALVES, E.; BARBOSA, J. F.; SOUZA, R. M. Constatação de Xylella fastidiosa em pecíolos e hipocótilos de cafeeiro com sintoma de mancha manteigosa. Ciência e Agrotecnologia, Lavras, v. 32, n.1, p.42-47, jan./fev., 2008.

LOPEZ, A. M. Q. Taxonomia, patogênese e controle de espécies do gênero Colletotrichum. Revisão Anual de Patologia de Plantas, Passo Fundo, v. 9, p. 291-338, 2001.

MILHOLLAND, R. D. Histopathology of strawberry infected with Colletotrichum fragariae.

Phytopathology, Saint Paul, v. 72, n. 11, p. 1434-1439, Nov. 1982.

NAIR, J.; CORBIN, J. B. Histopathology of Pinus radiata seedlings infected by Colletotrichum acutatum $\mathrm{f}$. sp. pinea. Phytopathology, Saint Paul, v. 71, n. 8, p. 777-783, Aug. 1981.

OROZCO MIRANDA, E. F. Caracterização morfológica, molecular, bioquímica e patogênica de isolados de Colletotrichum spp. associados ao cafeeiro em Minas Gerais e comparação com Colletotrichum kahawae. 2003. 147 p. Tese (Doutorado em Fitopatologia) - Universidade Federal de Lavras, Lavras, 2003.

PEREIRA, I. S. Compatibilidade vegetativa e sexual do complexo Glomerella-Colletotrichum associado ao cafeeiro e estudos histopatológicos. 2005. 92 p.

Dissertação (Mestrado em Fitopatologia) - Universidade Federal de Lavras, Lavras, 2005.

PEREIRA, I. S.; ABREU, M. S.; ALVES, E.; FERREIRA, J.

B. Estudos histopatológicos da interação

Colletotrichum gloeosporioides - cafeeiro. Bragantia, Campinas, v.68, n.1, p.117-123, 2009.

PORTO, M. D. M.; GRAU, C. R.; ZOETEN, G. A. de; GAARD, G. Histopathology of Colletotrichum trifolii on alfalfa. Phytopathology, Saint Paul, v. 78, n. 3, p. 345-349, Mar. 1988.

ROBERTS, R. G.; SNOW, J. P. Histopathology of cotton boll rot caused by Colletotrichum capsici.

Phytopathology, Saint Paul, v. 74, n. 4, p. 390-397, Apr. 1984. 
SUTTON, B. C. The genus Glomerella and its anamorph. In: BAILEY, J. A.; JEGUER, M. J. (Eds.).

Colletotrichum: biology, pathology and control. Wallingford: CAB International, 1992. p. 1-26.

VARGAS, G. E.; GONZALEZ, U. L. C. La mancha mantecosa del café causada por Colletotrichum spp. Turrialba, San José, v. 22, n. 2, p. 129-135, Apr./June 1972.
VOLTAN, R. B. Q.; CABRAL, L. P.; PARADELA FILHO, O. Avaliação preliminar do efeito do Colletotrichum spp. na estrutura de plantas de cafeeiro. In: CONGRESSO BRASILEIRO DE PESQUISAS CAFEEIRAS, 28., 2002, Caxambu, MG. Anais... Rio de Janeiro: MAPA/Procafé, 2002. p. 364-365.

WELLMAN, F. L. Blister spot of arabica coffee from virus in Costa Rica. Turrialba, San José, v. 7, n. 4, p. 116115, Oct./Dec. 1957. 